\title{
Edge Detection in Digital Image Using Statistical Method
}

\section{Huvaida Manzoor ${ }^{a}$ Dr.Yogeshwer Singh Randhawa ${ }^{b}$}

Abstract: Medicines have helped to make our lives easy. Drug industry is developing industry in terms of production as well as consumption. Medication has become very important in everyone's life as we are affected by so many diseases. But these medicines might be defected, tablets may be broken, there may be missing tablet in a strip and consumption of these drugs might be dangerous. This paper shows a method in digital image processing technique to find the defects in tablets. In this paper we use mathematical manipulation, to detect the defected tablet packet.

Keywords: Digital Image Processing, Morphology opening, Preprocessing.

\section{Introduction}

Digital image processing techniques and algorithms are applied on images in order to remove error. In this paper, we use digital image processing technique to detect the broken tablet. Such tablets are harmful to consume and may have many side effects. The inspection process is effective to detect the defects in tablets. Mathematical manipulation is used to detect the defect. This is done in Matlab10. First Image is taken and is converted into gray and then to binary and then noise is removed. Morphology operation is used to remove the noise. Morphology operation is applied on binary images therefore for this image is first converted into gray. This technique will find the defect in those tablets which are circular in shape.
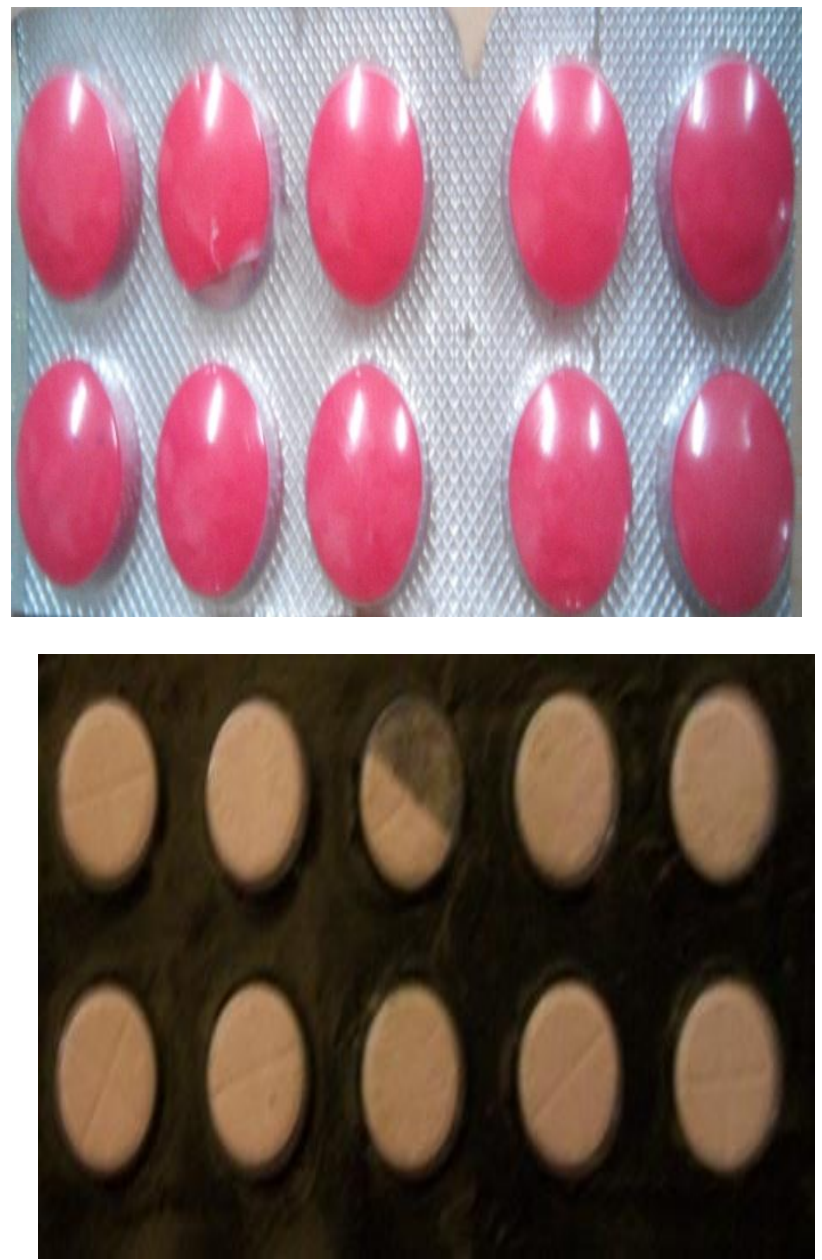

Figure 1 Different tablet packet with defect 


\section{Methodology}

In this paper, statistical method is used that is mathematically values are calculated. Tablet strip consists of various shapes like circular, rectangular, ellipse. In this paper, we have taken circular ones. We know that circular tablets have their particular area so if tablets are broken they deviate from the roundness. So in this way defect can be detected.

\section{Proposed Work}

In this paper, statistical method is used to find the defect in tablets. In order to find the defect, RGB image is converted into gray and then to binary. The binary image have noise so in order to remove noise, morphology opening is used. Boundaries of the output are detected after pre processing. After this process determine the roundness of tablet, find area and perimeter of each tablet. After calculating area and perimeter, find the metric. Metric closer to 1 indicates that tablet is not broken or is completely round.

Where ' $r$ ' is the radius of a circular tablet

$$
\text { area }=\pi r^{2}
$$

Where ' $\mathrm{d}$ ' is the diameter of tablet

$$
\text { perimeter }=\pi \times d
$$

Therefore, metric $=4 * \mathrm{pi}^{*}$ area/perimeter ${ }^{\wedge} 2$

So, metric closer to 1 indicates that tablet is not defected. Also no. of tablets are calculated which helps to determine the correct figure in a tablet strip. Counting can also help to find the pharmaceutical company. They can simply discard the strip containing less or greater no. of tablets.

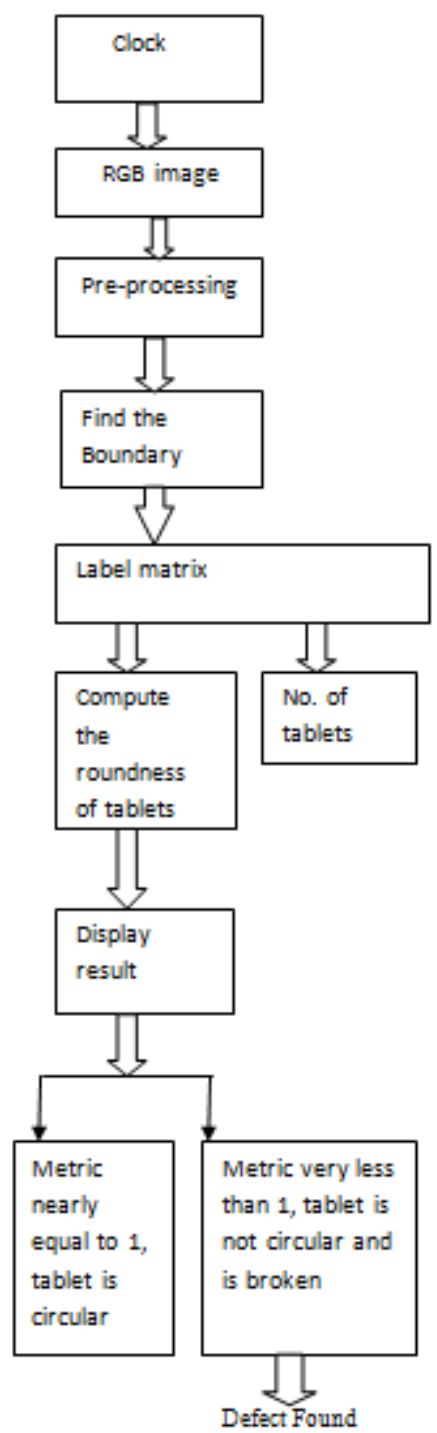

Figure 3 Block diagram shows how to find the defect 
Steps:

1. Capture a RGB image.

2. Convert the image into gray and then to binary.

3. Remove the noise using morphology opening.

4. Make the boundaries of all tablets.

5. Label the matrix.

6. Calculate the no. of tablets in a strip.

7. Now, compute the roundness of tablets.

8. Display the result, matrix equal to 1 means the tablet is round and is without any defect. However, matrix not equal to 1 means tablet is defected.

\section{Results}

Input Image

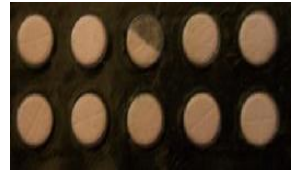

Gray Image

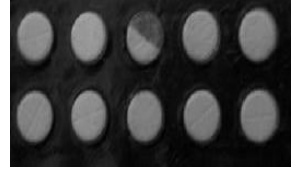

Figure 2 Defected Tablet Packet

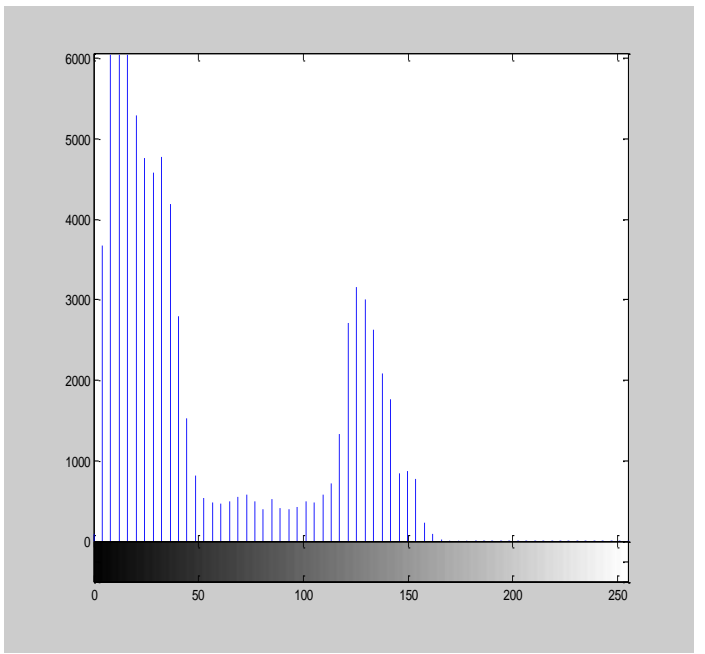

Figure 3 Histogram of tablet packet

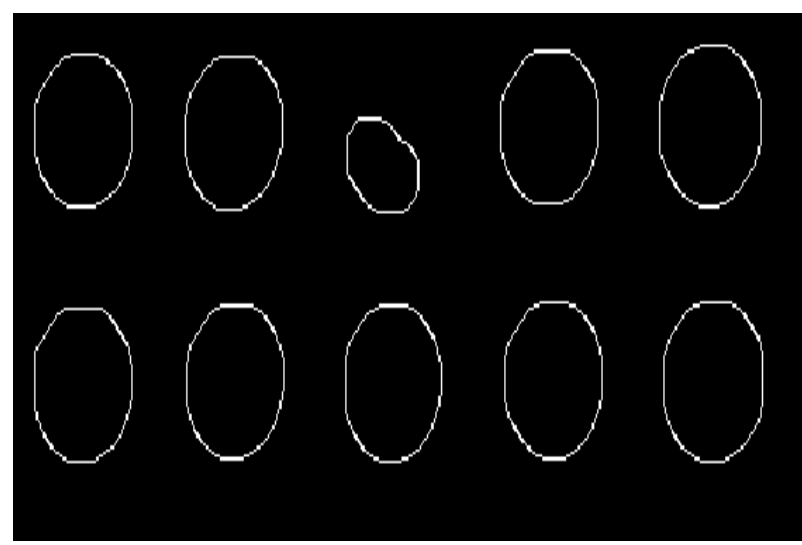

Figure 4 Removal of noise 


\section{Image with Noise \\ Cleaned Image

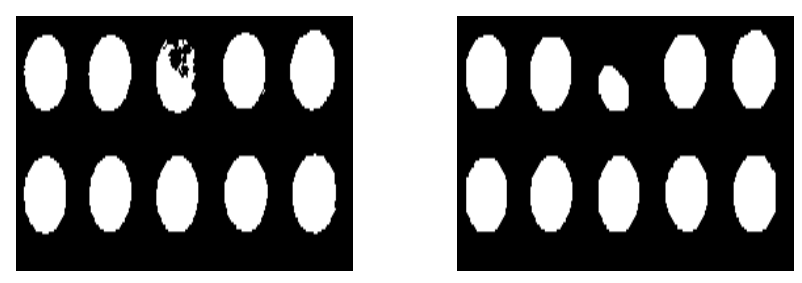

Figure 5 Edge Detection

Metrics closer to 1 indicate that the tablet is approximately round

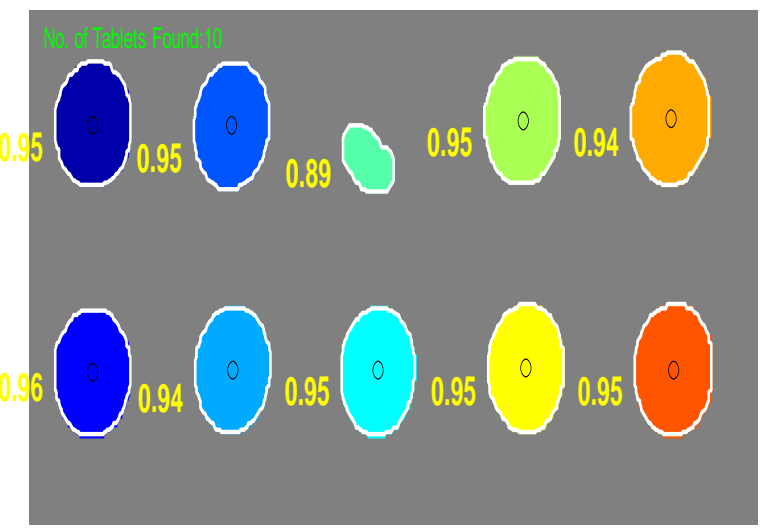

Figure 6 Defected tablet found

Input RGB image which is having defected tablet is first converted into gray image as shown in figure 2 . Histogram of the tablet packet is shown in figure3.gray image is then converted into binary image but the image is having some noise. Noise is removed by applying morphology opening. Figure 4 shows the cleaned image after removal of noise. Figure 5 shows the edges of tablets. Figure 6 shows the tablet whose metric is less than 1 is not round and is defected.

\section{Input Image}

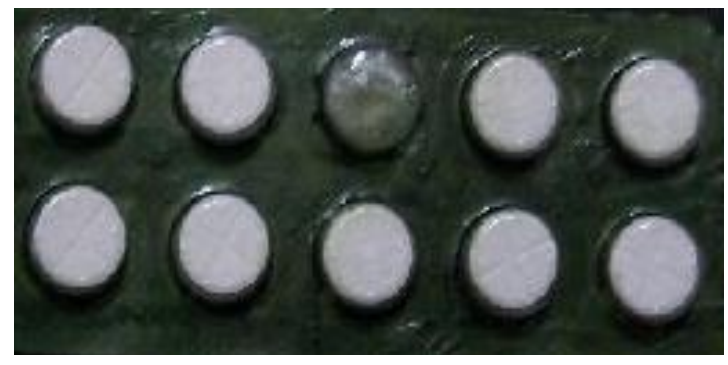

Figure 7 Tablet packet with missing tablet

Metrics closer to 1 indicate that the tablet is approximately round

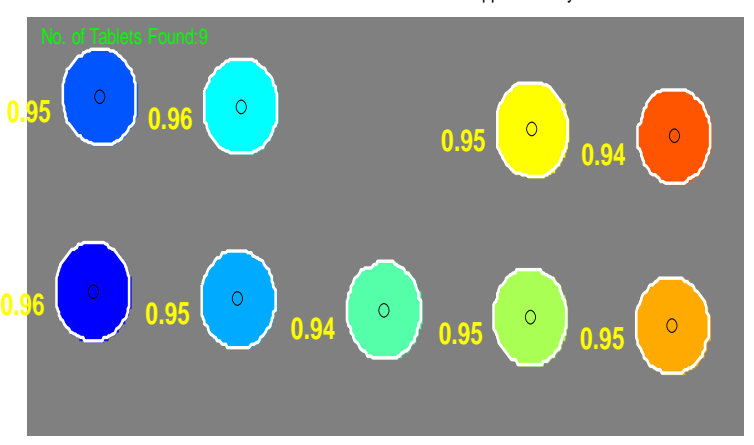

Figure 8 One missing tablet 
This method is also applied on tablet packet with missing tablet Figure 8 shows the tablet packet with one missing tablet. The tablet strip is of 10 tablets and the result shows only 9 tablets. This indicates that one tablet is missing in tablet packet. The whole process takes 2 Seconds of time. Figure 9 shows the screen shot after the whole program was executed. Linux Debian 5 has greater speed, so it is recommended to use this machine for operation.

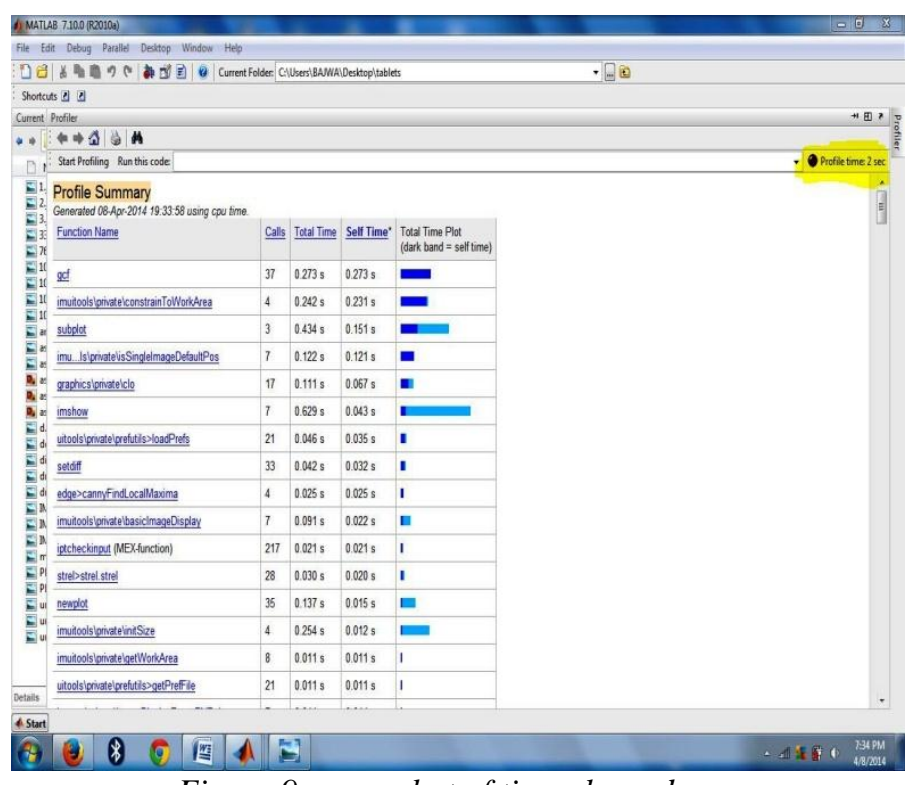

Figure 9 screenshot of time elapsed

\section{Conclusion}

This paper presents the application in drug industry using different techniques in digital image processing. It is implemented in matlab10 software. This paper mentions statistical method for detecting the anomalies in drugs. In this paper, defect of tablet is detected using area of a tablet, the tablets which deviate from the said area is considered as defected. We have taken the circular tablet, however this method can also be implemented on different shapes of tablet packet using their area. Instead morphology operation used for noise removal, any other method can be used. For efficient work, the time taken should be minimum.

\section{References:}

[1] Abha Sharma1,SugandhaArora "Inspection and Classification of Defects in Pharmaceutical Capsules Using Neural Network" International Journal of Engineering Research and Development ISSN: 2278-067X, Volume 1, Issue 10 (June 2012), PP.41-45

[2] StefanOprea, IoanLiță, Mariana Jurianu, Daniel AlexandruVişan, Ion BogdanCioc, "Digital Image Processing Applied in Drugs Industry for Detection of Broken Aspirin Tablets" Electronics, Communications and Computers Department, University of Pitesti Str.Targul din Vale Nr. 1 Pitesti, Romania,2008

[3] F Anthony C.karleff, Neil E.Scott\& Robert Muscedure, Flexible Design for a cost effective,high throughput Inspection system for pharmaceutical capsules. IEEE, 2008

[4] Dong-Su Kim, Wang-Heon Lee, In-So Kweon, "Automatic edge detection using 3x3 ideal binary pixel patterns and fuzzy-based edge thresholding," in Pattern Recognition Letters in 2004

[5] El-Khamy,S.E., Lotfy,M., El-Yamany,N.A.,"A Modified Fuzzy Sobel Edge Detector”,17. National Radio Science Conference, Feb.22-24 2000, Minufiya University, Egypt

[6] Miosso, C.J., Bauchspiess, A., "Fuzzy Inference System Applied to Edge Detection in Digital Images", Proceeding of the Brazilian Conference on Neural Networks, pp. 481-486, 2001

[7] HardeepKaur and Er.NidhiGarg, "Inspection of Defective Pharmaceutical Capsules using Harris Algorithm", International Journal of Advances in Electronics Engineering,2009

[8] R.Thilepa "A Paper On Automatic Fabrics Fault Processing Using Image Processing Technique in Matlab", Signal \& Image Processing : An International Journal(SIPIJ) Vol.1, No.2, December 2010.

[9] Peng Zhao and Shutao Li "Tablets Vision Inspection Approach Using Fourier Descriptors and Support Vector Machines" The $9^{\text {th }}$ International Conference for Young Computer Scientists,2008.

[9] Ramya.S,,Suchitra.J,Nadesh R.K”Detection of Broken Pharmaceutical Drugs using Enhanced Feature Extraction Technique”

[10] Nain, Neeta, et al. "Morphological Edge Detection and Corner Detection Algorithm Using Chain Encoding." IPCV 6 (2006): $520-$ 525 .

[11] TizhooshH.R.,"Fast fuzzy edge detection”, Proceedings of Fuzzy Information Processing Society, 2002, pp. 239-242.

[12] Abdallah A. Alshennawy, And Ayman A. Aly, "Edge Detection In Digital Images Using Fuzzy Logic Technique", In proceedings of World Academy of Science Engineering and Technology, Vol.51 , pp.178-186, 2009.

[13] Kaur, ErKiranpreet, ErVikramMutenja, and ErInderjeet Singh Gill. "Fuzzy Logic Based Image Edge Detection Algorithm in MATLAB." International Journal of Computer Applications 1.22 (2010): 55-58.

[14] Baig, Hasan,Jeong-A. Lee, and Jieun Lee. "Performance evaluation of CPU-GPU and CPU-only algorithms for detecting defective tablets through morphological imaging techniques." Information Systems and Technologies(CISTI),2012 7th Iberian Conference on.IEEE, 2012. 